\title{
Impact of Time Interval Between Chemoradiation and Surgery on Pathological Complete Response and Survival in Rectal Cancer
}

\author{
Ali Akbar ${ }^{1 *}$, Abu Bakar Hafeez Bhatti ${ }^{1}$, Samiullah Khan Niazi ${ }^{1}$, Amir Ali Syed ${ }^{1}$, \\ Shahid Khattak ${ }^{1}$, Syed Hassan Raza ${ }^{1}$, Ather Saeed Kazmi ${ }^{2}$
}

\begin{abstract}
Background: Limited data are available regarding the impact of time duration between chemoradiation (CRT) and surgery on pathological complete response (PCR). A PCR translates into better overall and disease free survival. The objective of this study was to determine effect of time duration on outcome after preoperative CRT in rectal cancer. Materials and Methods: A retrospective review of patients undergoing operations for rectal adenocarcinoma between January 2005 and December 2010 was performed. Patients were divided in two groups: Group 1 underwent surgery in $\leq 8$ weeks post neoadjuvant CRT and Group 2 after 8 weeks. Patient characteristics, surgical procedure, histopathological details and number of loco-regional and distant failures were compared. Expected 5 year overall survival and disease free survival was calculated using Kaplan Meier curves and significance was determined using the log rank test. Results: There were 66 patients in group 1 and 93 in group 2. No significant difference in PCR was observed between the two. However, estimated 5 year DFS was significantly higher in Group $1(66.7 \%)$ as compared to Group $2(53.8 \%)(P=0.04)$. Estimated overall 5 year overall survival was not significantly different at $68.2 \%$ versus $54.3 \%(P=0.09)$. Conclusions: Delaying surgery more than 8 weeks after preoperative CRT does not impact for PCR in rectal cancer.
\end{abstract}

Keywords: Rectal cancer - PCR - chemotherapy - radiation - delay in surgery - survival

Asian Pac J Cancer Prev, 17 (1), 89-93

\section{Introduction}

Colorectal cancer (CRC) is the fourth most common malignancy in United States and the second most frequent cause of cancer-related death (Jemal et al., 2010). Locally advanced colorectal cancer is a major public health problem (Beart et al., 2007; Bray et al., 2013). Multimodal therapy has become popular and implemented more widely in the last 20 years (Cervantes et al., 2007; Rubbia et al., 2007). Surgery remains the mainstay of treatment but introduction of neoadjuvant chemoradiation (CRT) in locally advanced rectal cancer (LARC) has translated into increased long term survival. LARC accounts for approximately half of all diagnosed rectal cancer cases with lymph node metastasis (Rubbia et al., 2004). The standard approach for locally advanced rectal cancer (T3 and/or node-positive tumors of the mid/low rectum is preoperative CRT combined with total mesorectal excision (TME). This results in high rate of local disease control, sphincter-preservation and patient survival (Sauer et al., 2004; Du et al. 2011; Popek et al., 2011; Cellini et al., 2012; NCCN, 2013; Petersen et al., 2013).

Surgery after completion of preoperative CRT is performed at 6-8 weeks to alleviate CRT related toxicity and to get sufficient time for tumor response. There is an emerging concept that tumor response to CRT is dependent on time period which may extend up to many months (Wang et al., 2005). But extending the interval between CRT and surgery is associated with radiation induced pelvic fibrosis resulting in surgical complications and increased risk of locoregional recurrence.

Since data is limited and results are conflicting, it remains unclear whether less or more than eight weeks is a better choice of time duration before surgical attempt (Stein et al., 2003; Moore et al., 2004; Tran et al., 2006; Supiot et al., 2006; Dolinsky et al., 2007; Kerr et al., 2008; Tulchinsky et al., 2008; Lim et al. 2008; Dhadda et al., 2009; Kalady et al., 2009). The objective of this study was to determine the impact of two different time durations between pre-operative CRT and surgery on outcome in patients with resectable rectal adenocarcinoma.

\section{Materials and Methods}

A retrospective review of patients who underwent surgery for rectal adenocarcinoma between January 
2005 and December 2010 at Shaukat Khanum Memorial Cancer Hospital and Research Centre was performed. A total of 159 patients who underwent surgical resection with curative intent and received preoperative CRT were included. Patients who underwent palliative surgery and patients in whom PCR could not be determined were excluded.

Associated work up and planning has been discussed elsewhere (Akbar et al., 2014). The standard protocol was to administer preoperative CRT in T3/T4 and/or clinically node positive tumors. The standard chemotherapy regimen was to give 4 cycles of Capecitabine and Oxaliplatin 3 weeks apart. Each cycle consisted of Capecitabine $1000 \mathrm{mg} / \mathrm{m}^{2}$ oral twice daily on Day 1 and 14 and Oxaliplatin $130 \mathrm{mg} / \mathrm{m}^{2}$ intravenous on Day 1 . In the concurrent setting, $825 \mathrm{mg} / \mathrm{m}^{2}$ of Capecitabine was given orally twice daily with radiation. A total of $50.4 \mathrm{~Gy}$ of radiation was administered in 28 fractions with 1.8 Gy per fraction. Details of follow up have been reported before (Bhatti et al., 2015)

Patient demographics and clinicopathological variables were compared. Patients were divided into two groups. Group 1 underwent surgery up to or less than 8 weeks after CRT and Group 2 later than 8 weeks. The primary outcome of interest was pathological complete response (pCR). Adverse events and 5 year disease free survival (DFS) and overall survival (OS) was also determined. Disease free survival was defined as time between date of surgery and date of relapse. Relapse included local, regional and distant failures. Overall survival was defined as time between date of surgery and date of death or last follow-up. Overall 5 year survival was calculated using Kaplan Meier survival curves and Log rank test was used to determine significance. A P value $<0.05$ was considered significant for all calculations.

\section{Results}

Patient characteristics

A total of 159 patients with rectal cancer underwent surgical resection. Out of these 66(42\%) underwent

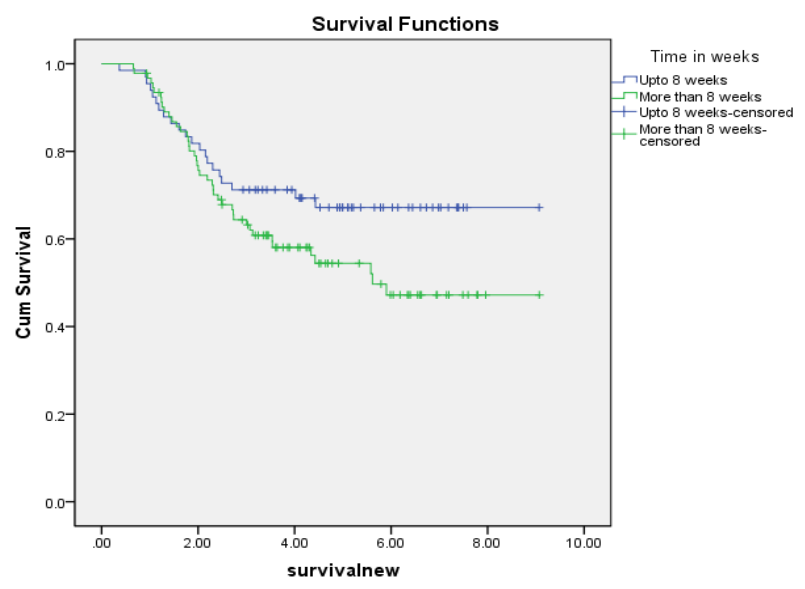

Figure 1. Estimated 5 year overall survival between patients with CRT to surgery duration $\leq 8$ weeks or $>8$ weeks

Table 1. Patient characteristics

\begin{tabular}{|c|c|c|c|c|c|c|c|}
\hline & & $\begin{array}{l}\text { Group } 1 \\
\text { Number }\end{array}$ & $\begin{array}{l}\text { Percent } \\
\text { Number }\end{array}$ & Group 2 & Percent & Total & $\mathrm{P}$ value \\
\hline \multirow[t]{2}{*}{ Gender } & Male & 43 & 65 & 63 & 67 & 106 & 0.73 \\
\hline & Female & 23 & 35 & 30 & 33 & 53 & \\
\hline \multirow[t]{2}{*}{ Family history } & Yes & 0 & 0 & 7 & 7.5 & 7 & $0.05 *$ \\
\hline & No & 66 & 100 & 86 & 92.5 & 152 & \\
\hline \multirow[t]{2}{*}{ Age group } & Age $>30$ years & 49 & 75 & 76 & 82 & 125 & 0.2 \\
\hline & Age $\leq 30$ years & 17 & 25 & 17 & 18 & 34 & \\
\hline \multirow[t]{3}{*}{ Distance from anal verge $(\mathrm{cm})$} & $0-5$ & 52 & 78 & 63 & 67 & 115 & 0.2 \\
\hline & 10-Jun & 13 & 20 & 26 & 27 & 39 & \\
\hline & $>10$ & 1 & 2 & 4 & 6 & 5 & \\
\hline \multirow[t]{3}{*}{ Tumor stage } & 2 & 3 & 5 & 12 & 12 & 15 & 0.19 \\
\hline & 3 & 45 & 68 & 60 & 64 & 105 & \\
\hline & 4 & 18 & 27 & 21 & 24 & 39 & \\
\hline \multirow[t]{3}{*}{ Preoperative nodal stage } & 0 & 9 & 13 & 15 & 16 & 24 & 0.66 \\
\hline & 1 & 15 & 22 & 16 & 17 & 31 & \\
\hline & 2 & 42 & 65 & 62 & 67 & 104 & \\
\hline \multirow[t]{2}{*}{ Clinical stage } & 2 & 10 & 15 & 15 & 16 & 25 & 0.86 \\
\hline & 3 & 56 & 85 & 78 & 84 & 134 & \\
\hline \multirow[t]{5}{*}{ Radiological T stage } & T0 & 6 & 9 & 5 & 5 & 11 & 0.06 \\
\hline & $\mathrm{T} 1$ & 3 & 4 & 5 & 5 & 8 & \\
\hline & $\mathrm{T} 2$ & 6 & 9 & 22 & 25 & 28 & \\
\hline & $\mathrm{T} 3$ & 39 & 60 & 38 & 40 & 77 & \\
\hline & $\mathrm{T} 4$ & 12 & 18 & 23 & 25 & 35 & \\
\hline \multirow[t]{3}{*}{ Radiological N stage } & No & 37 & 56 & 51 & 54 & 88 & 0.9 \\
\hline & N1 & 12 & 18 & 18 & 20 & 30 & \\
\hline & $\mathrm{N} 2$ & 17 & 26 & 24 & 26 & 41 & \\
\hline \multirow[t]{2}{*}{ Radiological stage } & Early & 36 & 55 & 53 & 55 & 89 & 0.8 \\
\hline & Late & 30 & 45 & 40 & 45 & 70 & \\
\hline
\end{tabular}


Table 2. Treatment Given

\begin{tabular}{|c|c|c|c|c|c|c|c|}
\hline & & $\begin{array}{l}\text { Group } 1 \\
\text { Number }\end{array}$ & Percentage & $\begin{array}{l}\text { Group } 2 \\
\text { Number }\end{array}$ & Percentage & & \\
\hline \multirow[t]{2}{*}{ Treatment Given } & Induction chemo given & 39 & 59 & 54 & 59 & 93 & 0.89 \\
\hline & IC not given & 27 & 41 & 39 & 41 & 66 & \\
\hline \multirow[t]{4}{*}{ Surgical procedure } & APR & 37 & 56 & 51 & 54 & 88 & 0.67 \\
\hline & Low AR & 20 & 30 & 32 & 34 & 52 & \\
\hline & ULAR & 8 & 12 & 7 & 7 & 15 & \\
\hline & Others & 1 & 2 & 3 & 5 & 4 & \\
\hline \multirow[t]{2}{*}{ Surgical method } & Lap & 18 & 27 & 37 & 40 & 55 & 0.1 \\
\hline & Open & 48 & 73 & 56 & 60 & 104 & \\
\hline
\end{tabular}

Table 3. Chemoradiation Induced Toxicity

\begin{tabular}{lccccccrr}
\hline & $\begin{array}{c}\text { Gastrointestinal } \\
\mathrm{n}=18\end{array}$ & Percentage & $\begin{array}{c}\text { Neurological } \\
\mathrm{n}=18\end{array}$ & Percentage & $\begin{array}{c}\text { Myelosuppression } \\
\mathrm{n}=2\end{array}$ & $\begin{array}{c}\text { Percentage } \\
\mathrm{n}=1\end{array}$ & $\begin{array}{c}\text { Others } \\
\text { Percent } \\
\text { age }\end{array}$ & $\begin{array}{r}\text { Total } \\
\mathrm{n}=39\end{array}$ \\
\hline Toxicity & & & & & & & & \\
Grade I & 1 & 6 & 8 & 44 & 0 & 0 & 0 & 0 \\
Grade II & 4 & 22 & 10 & 56 & 0 & 0 & 1 & 100 \\
Grade III & 13 & 72 & 0 & 0 & 2 & 100 & 0 & 0 \\
\hline
\end{tabular}

Table 4. Distribution of histopathological variables between the two groups

\begin{tabular}{|c|c|c|c|c|c|c|c|}
\hline & & $\begin{array}{c}\text { Group1 } \\
\text { Number }\end{array}$ & Percentage & $\begin{array}{l}\text { Group } 2 \\
\text { Number }\end{array}$ & Percentage & Total & $P$ value \\
\hline \multirow[t]{2}{*}{ TME } & Complete & 66 & 100 & 89 & 96 & 155 & 0.08 \\
\hline & Incomplete & 0 & 0 & 4 & 4 & 4 & \\
\hline \multirow[t]{2}{*}{ PCR } & Yes & 20 & 30 & 21 & 33 & 41 & 0.2 \\
\hline & No & 46 & 70 & 72 & 77 & 118 & \\
\hline \multirow[t]{4}{*}{ Grade } & Well & 14 & 21 & 18 & 19 & 32 & 0.79 \\
\hline & Moderate & 40 & 60 & 55 & 59 & 95 & \\
\hline & Poor & 11 & 16 & 16 & 17 & 27 & \\
\hline & Undifferentiated & 1 & 3 & 4 & 5 & 5 & \\
\hline \multirow[t]{2}{*}{ Mucinous } & Yes & 26 & 39 & 35 & 28 & 61 & 0.22 \\
\hline & No & 38 & 61 & 58 & 62 & 96 & \\
\hline \multirow[t]{2}{*}{ LV invasion } & Yes & 5 & 16 & 11 & 11 & 16 & 0.5 \\
\hline & No & 56 & 84 & 77 & 89 & 133 & \\
\hline \multirow[t]{3}{*}{ Path Nodal } & 0 & 37 & 56 & 58 & 63 & 95 & 0.72 \\
\hline & 1 & 12 & 18 & 14 & 15 & 26 & \\
\hline & 2 & 17 & 26 & 21 & 22 & 38 & \\
\hline \multirow[t]{5}{*}{ Pthological T Stage } & 0 & 20 & 31 & 23 & 24 & 43 & 0.65 \\
\hline & 1 & 2 & 3 & 6 & 6 & 8 & \\
\hline & 2 & 8 & 12 & 17 & 18 & 25 & \\
\hline & 3 & 32 & 48 & 41 & 44 & 73 & \\
\hline & 4 & 4 & 6 & 6 & 8 & 10 & \\
\hline \multirow[t]{4}{*}{ Pathological Stage } & 0 & 20 & 30 & 21 & 24 & 41 & 0.16 \\
\hline & 1 & 5 & 7 & 18 & 19 & 23 & \\
\hline & 2 & 12 & 18 & 19 & 20 & 31 & \\
\hline & 3 & 29 & 45 & 35 & 37 & 64 & \\
\hline
\end{tabular}

surgery within 8 weeks and 93 after 8 weeks of CRT. Median follow up was 3.6 years. No significant difference in demographics, clinical stage and treatments offered was observed between the two groups as shown in Tables 1 and 2. Significant difference was present between the two groups with respect to family history and clinical stage of tumor. As shown in Table 3, gastrointestinal and neurological toxicity was most common and seen in $18(11.3 \%)$ patients. Overall $13(38.5 \%)$ patients had grade III toxicity.

\section{Histopathological variables}

There was no significant difference between grade, presence of mucin, LV invasion, nodal stage, pathological $\mathrm{T}$ stage and histopathological stage between the two groups as shown in Table 4. A PCR was observed in $20(12.55 \%)$ patient in $\leq 8$ weeks group and $21(13.25 \%)$ in more than 8 weeks group with no significance. Only $4(2.5 \%)$ patients had incomplete TME all were in more than 8 weeks groups as shown in (Table 4)

\section{Outcome}

Out of 66 patients, 22(31.8\%) experienced a relapse 
Table 5. Pattern of Relapse between The Two Groups

\begin{tabular}{|c|c|c|c|c|c|c|c|}
\hline & & $\begin{array}{l}\text { Group } 1 \\
\text { Number }\end{array}$ & Percentage & $\begin{array}{l}\text { Group } 2 \\
\text { Number }\end{array}$ & Percentage & Total & $\mathrm{P}$ value \\
\hline \multirow{2}{*}{ Overall recurrence } & Yes & 22 & 33 & 43 & 46 & 65 & 0.1 \\
\hline & No & 44 & 67 & 50 & 54 & 94 & \\
\hline \multirow[t]{3}{*}{ Recurrence } & None & 44 & 67 & 50 & 53 & 94 & 0.096 \\
\hline & Locoregional & 8 & 12 & 24 & 25 & 32 & \\
\hline & Distant & 14 & 21 & 19 & 22 & 33 & \\
\hline \multirow[t]{2}{*}{ Status } & Alive & 45 & 69 & 50 & 53 & 95 & 0.06 \\
\hline & Dead & 21 & 31 & 43 & 47 & 64 & \\
\hline
\end{tabular}

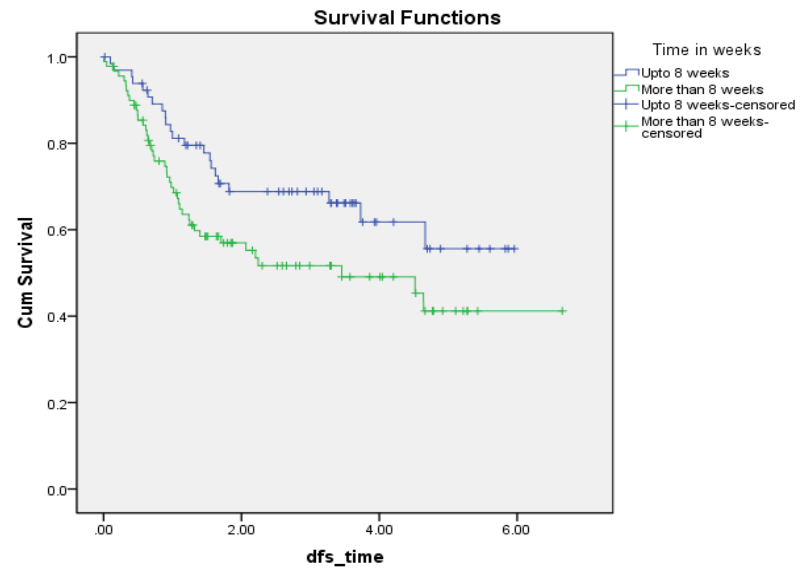

Figure 2. Estimated 5 year disease free survival between patients with CRT to surgery duration $\leq 8$ weeks or $>8$ weeks

in Group1 while 43(46.2\%) in Group 2 (Table 5). Median DFS was $1.8(0.01-6.6)$ years and $1.2(0.1-5.6)$ years for Group I and II respectively. Median overall survival was $3.8(.37-8.53)$ years and $2.46(0.93-9.07)$ years for Group I and Group II respectively. Estimated overall 5 year survival was $68.2 \%$ versus $54.3 \%$ in Group1 and 2 respectively and was not significantly different $(\mathrm{P}=0.09)$ as shown in Figure 1. Disease free survival was $66.7 \%$ versus $53.8 \%$ and was significantly different $(\mathrm{P}=0.04)$ shown in Figure 2.

\section{Discussion}

Precise time duration between preoperative CRT and surgery in LARC has been controversial in the past. It was first studied in R90-91 trial (Francois et al., 1999). It was a randomized controlled trial in which 201 patients were randomized to undergo surgery at 2 weeks or 6-8weeks after completion of radiotherapy. The results showed that patients with longer time duration between CRT and surgery had a better tumor response and pathological down staging. This 6-8-week interval has become a routine practice after CRT for rectal cancer. We did not find any significant difference in PCR rates between the two groups. This is consistent with the larger retrospective cohort study on 397 patients with PCR rate of 14 and $15 \%$ respectively in the two groups (Lim et al., 2008). Similar results have been demonstrated elsewhere (Moore et al., 2004; Dolinsky et al., 2007; Kerr et al., 2008). Kalady and colleagues, however, demonstrated a significant difference in PCR rates i.e. $30 \%$ versus $16 \%$ between patient groups with 8 weeks time duration as the cutoff. (Kalady et al., 2009).

An important modality not discussed in previously published studies is induction chemotherapy before chemoradiotherapy. In the current study induction chemotherapy was routinely employed in locally advanced rectal cancer and increased PCR rate up to $30 \%$.

We observed it better DFS and OS in patients operated within the 8 week cut-off despite a comparable PCR rate. We believe that patients operated after 8 weeks were more likely to have intense fibrosis with loss of surgical planes making it difficult to identify oncological planes clearly. There was a gender predilection for male patients in the current study. Male pelvis is narrower and in the background of intense fibrosis further increases the risk of non-oncological surgery. Probably, these factors translated into reduced local and distant failures with favorable survival outcome in patients operated within 8 weeks. The results of our study are supported by a retrospective multivariate analysis of 102 patients with locally advanced rectal cancer demonstrating a negative impact on DFS and OS with longer CRT-Surgery duration (Supiot et al., 2006).

The impact of CRT-surgery duration on survival has also been a matter of debate. Studies have demonstrated improved prognosis after longer CRT-surgery duration (Campos et al., 2001; Coucke et al., 2004; Tulchinsky et al., 2008; Wolthius et al., 2012).

Limitations of the current study include its retrospective design and relatively small sample size makes it difficult to generalize the results. Finally the results are based on only those patients who underwent surgery. Patients who did not proceed to surgery after CRT because of treatment-related toxicity, an inadequate response or disease progression were not recorded in the study. We are also unable to comment upon post operative complication rates between the two groups of patients and it is likely that they were significantly different. However, surgical morbidity assessment was not objective of this study.

The present study demonstrates no significant difference in PCR rates between patients operated within or after 8 weeks of preoperative chemoradiotherapy. Since PCR is a marker of better prognosis, this should translate into comparable DFS and OS in these two groups of patients. The different outcomes observed in the current study might be representative of other significant factors that ultimately impact outcome and should be considered when deciding upon appropriate time duration between 
Time Interval between Chemoradiationa nd Surgery and Pathological Complete Response in Rectal Cancer in Pakistan

surgery and preoperative chemoradiotherapy.

\section{References}

Akbar A, Bhatti AB, Khattak S, et al (2014). Outcome of rectal cancer in patients aged 30 years or less in the Pakistani population. Asian Pac J Cancer Prev, 15, 6339-42

Beart RW Jr (2007). Multidisciplinary management of patients with advanced rectal cancer. Clin Cancer Res, 13, 6890-93

Bhatti AB, Waheed A, Hafeez A, et al (2015).Can induction chemotherapy before concurrent chemoradiation impact circumferential resection marginpositivity and survival in low rectal cancers? Asian Pac J Cancer Prev, 16, 2993-8

Bray F, Ren JS, Masuyer E, et al (2013). Estimates of global cancer prevalence for 27 sites in the adult population in 2008. Int J Cancer, 132, 1133-45.

Cellini F, Valentini V (2012). Current perspectives on preoperative integrated treatments for locally advanced rectal cancer: a review of agreement and controversies. Oncol Williston Park, 26, 730-5.

Cervantes A, Rodriguez-Braun E, Navarro S, et al (2007). Integrative decisions in rectal cancer. Ann Oncol, 18, 127131.

Cohen SM, Neugut AI (2004). Adjuvant therapy for rectal cancer in the elderly. Drugs Aging, 21, 437-451

Coucke PA, Notter M, Matter M, et al (2006). Effect of timing of surgery on survival after preoperative hyperfractionated accelerated radiotherapy (HART) for locally advanced rectal cancer (LARC): is it a matter of days? Acta Oncol, 45, 1086-93

De Campos-Lobato LF, Geisler DP, da Luz Moreira A, et al (2011). Neoadjuvant therapy for rectal cancer: the impact of longer interval between chemoradiation and surgery. $J$ Gastrointest Surg, 15, 444-50

Dhadda AS, Zaitoun AM, Bessell EM (2009). Regression of rectal cancer with radiotherapy with or without concurrent capecitabine - optimising the timing of surgical resection. Clin Oncol, 21, 23-31.

Dolinsky CM, Mahmoud NN, Mick R, et al (2007). Effect of time interval between surgery and preoperative chemoradiotherapy with 5-fluorouracil or 5-fluorouracil and oxaliplatin on outcomes in rectal cancer. J Surg Oncol, 96, 207-12.

Du CZ, Chen YC, Cai Y, et al (2011). Oncologic outcomes of primary and post-irradiated early stage rectal cancer: a retrospective cohort study. World J Gastroenterol, 17, 3229-34

Garcia-Aguilar J, Smith DD, Avila K, et al (2011). Timing of rectal cancer response to chemoradiation consortium. optimal timing of surgery after chemoradiation for advanced rectal cancer: preliminary results of a multicenter, nonrandomized phase II prospective trial. Ann Surg, 254, 97-102.

Jemal A, Siegel R, Xu J, et al (2010). Cancer statistics, $C A$ Cancer J Clin, 60, 277-300

Kalady MF, de Campos-Lobato LF, Stocchi L, et al (2009). Predictive factors of pathologic complete response after neoadjuvant chemoradiation for rectal cancer. Ann Surg. 250, 582-9

Kerr SF, Norton S, Glynne-Jones R (2008). Delaying surgery after neoadjuvant chemo radiotherapy for rectal cancer may reduce postoperative morbidity without compromising prognosis. Br J Surg, 95, 1534-40

Lim SB, Choi HS, Jeong SY, et al (2008). Optimal surgery time after preoperative chemoradiotherapy for locally advanced rectal cancers. Ann Surg, 248, 243-251.

Moore HG, Gittleman AE, Minsky BD, et al (2004). Rate of pathologic complete response with increased interval between preoperative combined modality therapy and rectal cancer resection. Dis Colon Rectum, 47, 279-86.

National Comprehensive Cancer Network (2013). NCCN clinical practice guidelines in oncology, Rectal cancer. Accessed: September, 26.

Petersen SH, Harling H, Kirkeby LT, et al (2012). Postoperative adjuvant chemotherapy in rectal cancer operated for cure. Cochrane Database Syst Rev, 3, 4078

Popek S, Tsikitis VL (2011). Neoadjuvant vs adjuvant pelvic radiotherapy for locally advanced rectal cancer: Which is superior? World J Gastroenterol, 17, 848-54

Rubbia-Brandt L, Giostra E, Brezault C, et al (2007). Importance of histological tumor response assessment in predicting the outcome in patients with colorectal liver metastases treated with neo-adjuvant chemotherapy followed by liver surgery. Ann Oncol, 18, 299-304

Sauer R, Becker H, Hohenberger W, et al (2004). Preoperative versus postoperative chemoradiotherapy for rectal cancer. N Engl J Med, 351, 1731-40.

Stein DE, Mahmoud NN, Anne PR, et al (2003). Longer time interval between completion of neoadjuvant chemoradiation and surgical resection does not improve downstaging of rectal carcinoma. Dis Colon Rectum, 46, 448-53

Supiot S, Bennouna J, Rio E, et al (2006). Negative influence of delayed surgery on survival after preoperative radiotherapy in rectal cancer. Colorectal Dis, 8, 430-5

Tran CL, Udani S, Holt A, et al (2006). Evaluation of safety of increased time interval between chemoradiation and resection for rectal cancer. Am J Surg, 192, 873-7

Tulchinsky H, Shmueli E, Figer A, et al (2008). An interval $>7$ weeks between neoadjuvant therapy and surgery improves pathologic complete response and disease-free survival in patients with locally advanced rectal cancer. Ann Surg Oncol, 15, 2661-7

Wang Y, Cummings B, Catton P, et al (2005). Primary radical external beam radiotherapy of rectal adenocarcinoma: long term outcome of 271 patients. Radiother Oncol, 77, 126-32.

Wolthuis AM, Penninckx F, Haustermans K, et al (2012). Impact of interval between neoadjuvant chemoradiotherapy and TME for locally advanced rectal cancer on pathologic response and oncologic outcome. Ann Surg Oncol, 19, $2833-41$ 